\title{
Milkweed loss in agricultural fields because of herbicide use: effect on the monarch butterfly population
}

\author{
JOHN M. PLEASANTS ${ }^{1}$ and KAREN S. OBERHAUSER ${ }^{2} \quad{ }^{1}$ Department of Ecology, \\ Evolution and Organismal Biology, Iowa State University, Ames, IA, USA and ${ }^{2}$ Department of Fisheries, Wildlife and Con- \\ servation Biology, University of Minnesota, St Paul, MN, USA
}

\begin{abstract}
The size of the Mexican overwintering population of monarch butterflies has decreased over the last decade. Approximately half of these butterflies come from the U.S. Midwest where larvae feed on common milkweed. There has been a large decline in milkweed in agricultural fields in the Midwest over the last decade. This loss is coincident with the increased use of glyphosate herbicide in conjunction with increased planting of genetically modified (GM) glyphosate-tolerant corn (maize) and soybeans (soya).

2. We investigate whether the decline in the size of the overwintering population can be attributed to a decline in monarch production owing to a loss of milkweeds in agricultural fields in the Midwest. We estimate Midwest annual monarch production using data on the number of monarch eggs per milkweed plant for milkweeds in different habitats, the density of milkweeds in different habitats, and the area occupied by those habitats on the landscape.

3. We estimate that there has been a $58 \%$ decline in milkweeds on the Midwest landscape and an $81 \%$ decline in monarch production in the Midwest from 1999 to 2010. Monarch production in the Midwest each year was positively correlated with the size of the subsequent overwintering population in Mexico. Taken together, these results strongly suggest that a loss of agricultural milkweeds is a major contributor to the decline in the monarch population.

4. The smaller monarch population size that has become the norm will make the species more vulnerable to other conservation threats.
\end{abstract}

Key words. Glyphosate, GMO, milkweed, monarch butterfly

\section{Introduction}

Monarch butterflies (Danaus plexippus L. Lepidoptera: Danainae) in the Eastern North American migratory population undergo a multi-generation annual cycle that includes wintering in central Mexico. In the spring, adults that have overwintered migrate north and reproduce in Texas and states to the north and east. Their offspring move farther north into much of the eastern half of the United States and southern Canada, and two to three more generations are produced (Cockrell et al., 1993; Malcolm et al., 1993; Prysby \& Oberhauser, 2004). Most adults that emerge after mid-August are in a state of reproductive diapause (Herman, 1985; Goehring \& Oberhauser, 2002) and

Correspondence: John M. Pleasants, Department of Ecology, Evolution and Organismal Biology, Iowa State University, Ames, IA 50011, USA. E-mail: jpleasan@iastate.edu migrate from the summer breeding range to their wintering grounds, where they remain until spring (Solensky, 2004).

Annual counts of the size of the overwintering population in Mexico indicate that the monarch population has been declining over the last decade and a half (Rendón-Salinas et al., 2011; Brower et al., 2011b). One possible explanation for this decline is that monarch production has been decreasing as a result of a reduction in the availability of the larval host plant. Monarch larvae feed primarily on milkweeds (genus Asclepias- Family Apocynaceae, subfamily Asclepiodeae). On the basis of milkweed cardenolide fingerprints, it has been estimated that $92 \%$ of the monarchs wintering in Mexico had fed as larvae on the common milkweed, Asclepias syriaca (Malcolm et al., 1993). Studies in Iowa found a large reduction in A. syriaca in corn (maize, Zea mays) and soybean (soya, Glycine max) fields from 1999 to 2009 (Hartzler \& Buhler, 2000; Hartzler, 2010). It is likely that a similar reduction has occurred throughout the region where corn and soybeans are predominantly grown. Eighty per cent of both 
corn and soybeans are grown in the Midwest (USDA, National Agricultural Statistics Service, 2011c), which is composed of the states of North and South Dakota, Nebraska, Kansas, Missouri, Iowa, Minnesota, Wisconsin, Illinois, Indiana, Michigan, and Ohio. A study in 2000 (Oberhauser et al., 2001) found that monarchs heavily used milkweeds in corn and soybean fields. On the basis of stable isotope analysis, Wassenaar and Hobson (1998) estimated that half of the monarchs overwintering in Mexico in 1997 came from the Midwest. Thus, the Midwestern United States is at the epicentre of a reduction in milkweeds in agricultural fields and is also an area that has in recent history contributed a large component of the monarch population. In this study, we estimate the magnitude of this milkweed loss and its consequences for monarch production.

Milkweed in agricultural fields has long been a concern for farmers as its presence reduces yield (Bhowmik, 1994). In the 1970s and 1980s, milkweed infestation in agricultural fields was viewed to be on the increase with 10.5 million ha infested in the north-central states (Martin \& Burnside, 1980). Herbicides have been increasingly used to control weeds in row crops. Many of these herbicides produce only moderate control of milkweed, but glyphosate, often referred to as Roundup ${ }^{\mathrm{TM}}$ (Monsanto, St. Louis, MO, USA), is more effective (Bhowmik, 1994; Pline et al., 2000). However, it also has a detrimental effect on crop plants, so until the development of genetically modified (GM) glyphosate-tolerant (Roundup Ready ${ }^{\mathrm{TM}}$, Monsanto) crop plants, herbicides other than glyphosate were used to control weeds. Glyphosate-tolerant soybeans were introduced in 1996 and had reached a $94 \%$ adoption level by 2011, and glyphosate-tolerant corn was introduced in 1998 and had reached a 72\% adoption level by 2011 (USDA, Economic Research Service, 2011). Glyphosate use in soybeans went from 1.4 million $\mathrm{kg}$ in 1994 to 41.7 million $\mathrm{kg}$ in 2006 (the last year for which data are available and when adoption of glyphosate-tolerant soybeans was $89 \%$ ) and glyphosate use in corn went from 1.8 million $\mathrm{kg}$ in 2000 to 28.5 million $\mathrm{kg}$ in 2010 when the adoption level was $70 \%$ (USDA, National Agricultural Statistics Service, 2011a,b).

The time period (1999-2009) over which the Iowa studies found a large reduction in $A$. syriaca in corn and soybean fields (Hartzler \& Buhler, 2000; Hartzler, 2010) is coincident with the period when use of glyphosate herbicide increased in conjunction with the increased adoption of glyphosate-tolerant corn and soybeans. It is very probable that a similar milkweed reduction has occurred throughout the Midwest because adoption levels of herbicide-tolerant crops are similar throughout this region (USDA, Economic Research Service, 2011). How much milkweed loss does this represent on a landscape scale? To address this question, we need information on the density of milkweeds in different habitats and the landscape area covered by those habitats. Common milkweed tends to be found in habitats with a moderate degree of disturbance, including roadsides, pastures, old fields, prairies and agricultural fields (Bhowmik, 1994). Multiple data sets provide information on the density of milkweeds in different habitats over the last decade. The studies by Hartzler and Buhler (2000) and Hartzler (2010) surveyed a number of milkweed habitats in Iowa, including agricultural fields. Additionally, a number of Midwest volunteers in the Monarch Larva Monitoring Project (2011), hereafter referred to as MLMP, measured milkweed density in their non-agricultural observation patches over several consecutive years. Milkweed density data can be combined with published statewide land-use data to estimate the number of milkweeds in different habitats. Some of the data sets we use come from Iowa because for some parameters only Iowa data are available. However, we use data from the Midwest as a whole whenever possible and make the case that the resulting estimates of monarch production are representative of the Midwest.

What is the significance of the loss of milkweeds in agricultural fields for monarchs? To address this issue, we need to estimate annual monarch production in the Midwest over the last decade to determine whether there has been a significant downward trend. Obtaining data to estimate production is difficult, despite the fact that the monarch butterfly is such a well-studied species. One approach would be to use the number of migrants that come out of the Midwest at the end of the summer as a measure of production. A monarch tagging programme begun 20 years ago (Monarch Watch, 2011) has been tracking migrating butterflies. The number of monarchs tagged shows a decline from 2004 to 2010 (Brower et al., 2011a). However, it is difficult to obtain accurate measures of production from this tagging programme because of the variability among the years in the number of person-hours involved in capture and tagging, the fall conditions when tagging occured and the locations where tagging occured. Alternatively, one could use counts of the number of migrating monarchs passing particular locations where they tend to be funnelled because of passage over water or geography. Such counts have been made for over a decade in upper Michigan and New Jersey (Davis, 2011) but these sites do not monitor monarchs from the Midwest.

Rather than trying to count adults, another approach to estimating Midwest monarch production is to focus on the number of eggs and larvae found on milkweed plants. This requires monitoring many patches of milkweed in different habitats, including agricultural fields. Production can then be estimated from the average number of monarchs per plant in each habitat and the number of milkweeds in each habitat on the landscape. We have combined several existing data sets that provide this information. The MLMP (2011), which has been operational for over a decade, provides data on egg and larva density on milkweeds. MLMP volunteers are located throughout the monarch breeding range and monitor sites of their choosing weekly over the summer months, reporting the number of plants (stems) monitored and the number of eggs and larvae observed. They learn the procedures of the project through workshops, by reading directions on the project website (MLMP, 2011) and via communication with the project managers (Prysby \& Oberhauser, 2004). The sites they monitor, however, are not in agricultural fields. But one of us (Pleasants) has monitored eggs and larvae on milkweeds in both agricultural fields and non-agricultural habitats for several years in central Iowa and a study with larger spatial scale quantified monarch density in both agricultural and non-agricultural habitats in 2000 (Oberhauser et al., 2001). We will make the case that the relative use of milkweeds in agricultural and non-agricultural habitats observed over those years can be extrapolated to provide 
data on monarch use of agricultural milkweeds in years where only MLMP data exist. There is a question of what aspect of production to use to estimate monarch population changes. The latest stage for which we have density data, and thus which is closest to actual production of adult monarchs, is the fifth instar (L5, the last larval instar). However, there are many factors that can affect survivorship from egg to L5 that have nothing to do with milkweed availability, such as predation and weather. Our goal was to examine the effect of milkweed resource limitation on monarch production. Consequently, we chose to focus on eggs per plant that represents potential production.

\section{Methods}

\section{Data sources for milkweed density}

Habitats in which milkweeds are found include primarily roadsides, corn fields, soybean fields, pastures, old fields, and land set aside from farming and enrolled in the Conservation Reserve Program (CRP). CRP land is typically planted to a variety of cover plants including grasses and forbs. To estimate milkweed densities in these habitats, we used data from several sources: Iowa censuses carried out in 1999 and 2009 (Hartzler \& Buhler, 2000; Hartzler, 2010), and data from some MLMP volunteers who measured milkweed density at their sites in several Midwest states. To calculate monarch production for each year, it is necessary to know how milkweed densities have changed over the last decade in non-agricultural and agricultural habitats.

Non-agricultural habitats. For roadsides, there was little observed change in milkweed density in Iowa between 1999 and 2009 (Hartzler, 2010) so we have assumed that milkweed density did not change in that habitat over the entire period of the analysis. Hartzler (2010) measured milkweed densities for CRP land and pastures in 1999 but not in 2009 so any change that may have occurred could not be determined from the Iowa data. However, a subset of MLMP volunteers $(n=16)$ measured milkweed density at their sites (which included natural areas, CRP land, pastures and old fields) for at least 4 years over this period (97 total observations). Measurements by individual MLMP volunteers did not cover the entire period but there were sufficiently long and overlapping sequences to provide a complete picture. Volunteers either measured the area of their site and did a complete count of milkweed stems, or used a modified belt transect to sample milkweed density in $1001 \times 1 \mathrm{~m}$ plots. We have used those data to estimate the change in milkweed density in CRP land and pasture land over the last decade.

For the data from the MLMP volunteers, we used log of milkweed density as the variate and used an SAS mixed model and restricted maximum likelihood estimation with fixed effects being 'habitat', 'year' and 'habitat by year'. We did not find a 'habitat by year' effect so we reran the analysis with this removed. There was a significant 'year' effect $\left(F_{1,85}=9.35\right.$,

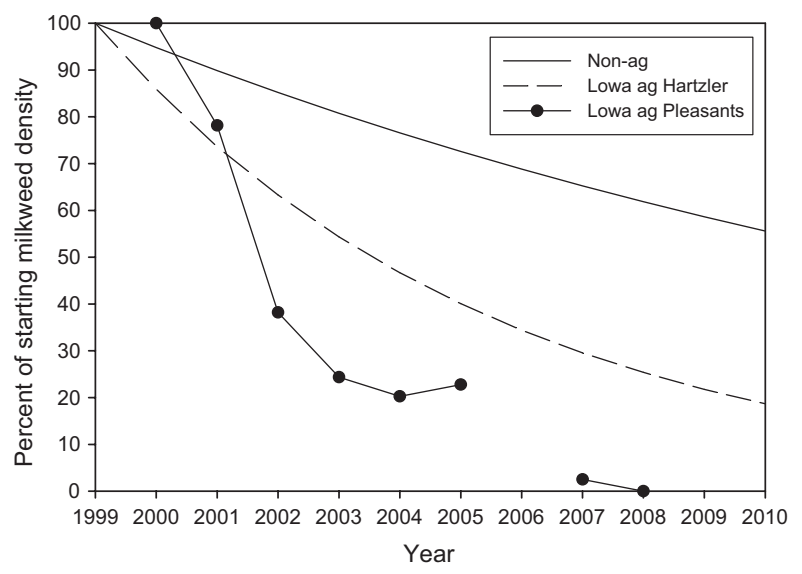

Fig. 1. Decline of milkweeds in agricultural and non-agricultural habitats. The line depicting the decline in non-agricultural habitats is based on a regression using data from MLMP volunteers. The line depicting the decline in agricultural habitats is based on an exponential decay function connecting the 1999 and 2009 values from the Iowa surveys (see Methods). Also shown is the proportional change in the number of milkweed stems in all monitored plots in seven agricultural fields in Iowa starting with 998 stems in 2000. The increase in milkweed stems observed in the agricultural sites in 2005 was attributed to the influence of fields where corn was planted 2 years in a row. Some agricultural fields received glyphosate herbicide treatment and others nonglyphosate treatment. No observations were made in 2006.

$P=0.003$ ). The slope of the regression (on a log scale) was -0.0536 , which corresponds to a decline in density of $5.2 \%$ per year. We found no 'habitat' effect so we applied the same rate of decline to both CRP land and pastures (Fig. 1).

Agricultural habitats. We have values for milkweed density in Iowa agricultural fields for 1999 and 2009 (Hartzler \& Buhler, 2000; Hartzler, 2010). To calculate milkweed density in fields for the intervening years, we have to make an assumption about the shape of the decline. Pleasants observed the change in the number of milkweeds in plots in seven agricultural fields in Iowa from 2000 to 2008 (Fig. 1). The observed decline is best described by an exponential decay function. Such a function is also consistent with more acres of glyphosate-tolerant corn and soybeans being planted each year over the last decade (USDA, Economic Research Service, 2011). We have therefore assumed that milkweed density in fields decreased as an exponential decay function from its 1999 value to its 2009 value (see Table 1). This corresponds to a $14.2 \%$ decline per year (Fig. 1). Other decline functions, ranging from a linear decline to a more precipitous exponential decay, had no significant effect on the overall results.

\section{Data sources for land use}

We obtained data on the acres occupied by roadsides and pastures on the Iowa landscape in 2002 from Lubowski et al. (2006) and, because no more recent data exist, we have assumed the 
Table 1. Estimates of the amount of milkweed in non-agricultural habitats, agricultural fields and total milkweeds in Iowa from 1999 to 2010.

\begin{tabular}{|c|c|c|c|c|c|}
\hline \multirow[b]{2}{*}{ Year } & \multicolumn{5}{|c|}{ Milkweeds in non-agricultural habitats } \\
\hline & CRP hectares* & CRP mlkwds $†$ & Pasture mlkwds & Roadside mlkwds§ & Total non-ag mlkwds \\
\hline 1999 & 601 & 127.4 & 19.8 & 38.2 & 185.4 \\
\hline 2000 & 647 & 130.1 & 18.8 & 38.2 & 187.1 \\
\hline 2001 & 729 & 139.0 & 17.8 & 38.2 & 195.0 \\
\hline 2002 & 755 & 136.4 & 16.9 & 38.2 & 191.5 \\
\hline 2003 & 762 & 130.5 & 16.0 & 38.2 & 184.7 \\
\hline 2004 & 767 & 124.5 & 15.2 & 38.2 & 177.9 \\
\hline 2005 & 776 & 119.5 & 14.4 & 38.2 & 172.0 \\
\hline 2006 & 793 & 115.7 & 13.6 & 38.2 & 167.5 \\
\hline 2007 & 797 & 110.3 & 12.9 & 38.2 & 161.4 \\
\hline 2008 & 733 & 96.2 & 12.3 & 38.2 & 146.6 \\
\hline 2009 & 690 & 85.8 & 11.6 & 38.2 & 135.7 \\
\hline 2010 & 663 & 78.2 & 11.0 & 38.2 & 127.4 \\
\hline \multirow[t]{2}{*}{ Year } & \multicolumn{5}{|c|}{ Milkweeds in agricultural fields } \\
\hline & Total ag hectares** & Mlkwd density $\dagger \dagger$ & Total ag mlkwdst+ & & Total milkweeds§§ \\
\hline 1999 & 9267 & 23.00 & 213.2 & & 398.5 \\
\hline 2000 & 9308 & 19.75 & 183.8 & & 370.9 \\
\hline 2001 & 9186 & 16.92 & 155.4 & & 350.4 \\
\hline 2002 & 9166 & 14.55 & 133.4 & & 324.8 \\
\hline 2003 & 9267 & 12.49 & 115.8 & & 300.4 \\
\hline 2004 & 9267 & 10.73 & 99.4 & & 277.3 \\
\hline 2005 & 9247 & 9.21 & 85.2 & & 257.2 \\
\hline 2006 & 9207 & 7.91 & 72.8 & & 240.3 \\
\hline 2007 & 9247 & 6.79 & 62.8 & & 224.2 \\
\hline 2008 & 9328 & 5.83 & 54.4 & & 201.0 \\
\hline 2009 & 9389 & 5.00 & 46.9 & & 182.6 \\
\hline 2010 & 9389 & 4.29 & 40.3 & & 167.6 \\
\hline
\end{tabular}

$* \times 1000$; from USDA Conservation Programs (2010).

$\dagger \mathrm{m}^{2} \times 1000$; CRP ha $\times 212 \mathrm{~m}^{2} \mathrm{ha}^{-1}$ (milkweed density from H\&B, 2000) $\times 0.948^{x}$ (where $x=0$ for 1999).

$\$ \mathrm{~m}^{2} \times 1000$; 1416 ha (Lubowski et al., 2006) $\times 14 \mathrm{~m}^{2} \mathrm{ha}^{-1}$ (milkweed density from H\&B, 2000) $\times 0.948^{x}$ (where $x=0$ for 1999).

$\$ \mathrm{~m}^{2} \times 1000 ; 386$ ha (Lubowski et al., 2006) $\times 99 \mathrm{~m}^{2} \mathrm{ha}^{-1}$ (average milkweed density from H\&B, 2000 and H, 2010).

$\uparrow \mathrm{m}^{2} \times 1000$; Conservation Reserve Program (CRP) milkweeds + Pasture milkweeds + Roadside milkweeds.

** $\times 1000$; from Iowa State Ag. Statistics (2010).

$\dagger \mathrm{m}^{2} \mathrm{ha}^{-1}$; 1999 value from H\&B (2000), 2009 value from H (2010); others $=1999$ value $\times 0.858^{x,}$ where $x=0$ for 1999.

$\$ \mathrm{~m}^{2} \times 1000 ; \mathrm{Ag}$ ha $\times$ Milkweed density.

$\S \S \mathrm{m}^{2} \times 1000$.

acres in roadside and pasture have not changed substantially over the last decade. Data on the acres planted to corn or soybeans by year were obtained from Iowa State Agricultural Statistics (2010) and the amount of Iowa CRP land from the USDA Conservation Programs (2010).

\section{Estimating monarch use of non-agricultural milkweeds}

To estimate monarch use of non-agricultural milkweeds, we used data on the number of monarch eggs per milkweed stem from the MLMP. We examined MLMP data from 1999 to 2010 for sampling localities within the Midwest (eastern Kansas, eastern Nebraska, eastern North and South Dakota, Minnesota, Iowa, Missouri, Wisconsin, Illinois, Michigan, Indiana and western Ohio). Sites were excluded in any given year if the average number of milk- weeds monitored was $<25$ and if there were fewer than five sampling events in July and August. We also excluded garden sites because they represent a minor component of milkweeds on the landscape. Sites were excluded if volunteers observed more larvae than eggs because these volunteers may not have been able to discern monarch eggs accurately. We initially divided sites into two groups based on the habitats in which the milkweeds were found: 'natural areas' (prairies or nature preserves) and 'other' (pastures, old fields, roadsides and CRP land); there were no sites in agricultural fields. However, 'natural areas' and 'other' were not significantly different from each other in egg density and were combined in the analysis into a single 'non-agricultural' category.

For any site, the number of eggs per plant varies over the course of the season. However, there is a population build-up during July and August when the second/third generation 
occurs (MLMP, 2011). We used egg density at the peak of this build-up as a metric of annual production. For each year, our estimate of production was based on the average maximum egg density over all MLMP sites. This metric does not include all of the annual production but does allow us to examine the relative differences in production among years.

\section{Monarch use of milkweeds in agricultural fields}

Pleasants monitored milkweed populations and monarch activity in agricultural fields and non-agricultural habitats in Iowa from 2000 to 2003. Initially six study sites were selected. Each site included a field planted to soybeans, another field adjacent or nearby that was planted to corn and a nearby non-agricultural habitat. Non-agricultural habitats included natural areas, pastures, old fields and roadsides. CRP land was not explicitly included as a habitat type but the non-agricultural habitats selected are similar in vegetative characteristics to CRP land. Sites were all located within a $10 \mathrm{~km}$ radius of Ames, Iowa, except for one site located $40 \mathrm{~km}$ south of Ames. Over the years of study, a few sites were removed from monitoring for logistical reasons and a few others added but in all years, both agricultural and non-agricultural plots were examined. Within each site, patches of milkweeds were marked (milkweed plots). These patches were relatively discrete units that ranged in area from $3 \times 3$ to $6 \times 10 \mathrm{~m}$ and contained $10-150$ milkweed stems. In each field, approximately 10 milkweed plots were chosen and mapped using a global positioning system device so they could be relocated in subsequent years. Sites were visited at weekly intervals: in 2000 from late May to late August; in 2001 from early July through late August; and in 2002 and 2003 from early June to late August. During each visit, every milkweed stem in each milkweed plot was inspected for monarch eggs and larvae.

As described above, we used the maximum number of eggs per stem observed during the weekly censuses from July through August as the measure of production. Egg densities in different non-agricultural habitat types were not statistically different, so they were combined into one category. Egg densities on milkweed in corn and soybean fields in any year were not statistically different from each other and were combined into a single cate- gory. The results are shown in Table 2. Egg densities on milkweeds in agricultural fields were significantly higher than on milkweeds in non-agricultural habitats in each year by an average factor of 3.89 .

\section{Estimating potential monarch production}

Potential monarch production for any year is equal to the sum of egg production from two sources: non-agricultural and agricultural milkweeds. To calculate production from non-agricultural milkweeds, we first determined the number of milkweeds in non-agricultural habitats. This is equal to the area occupied by each habitat type (CRP land, pasture and roadside) multiplied by the density of milkweeds in that habitat (see Table 1).We then multiplied the total number of non-agricultural milkweeds by the average number of eggs per non-agricultural milkweed plant for that year from the MLMP data (see Table 3). To calculate production from agricultural fields, we first determined the number of milkweeds in fields. This is equal to the area occupied by agricultural land multiplied by the milkweed density in fields (see Table 1). The number of agricultural milkweeds in each year was multiplied by the eggs per agricultural milkweed plant. For the years 2000-2003, we used Iowa data for the eggs per agricultural milkweed (from Table 2). For each of the other years, the egg density on agricultural milkweeds was taken to be 3.89 times the MLMP value for that year (see Table 3).

\section{Results}

Estimates of milkweed numbers on the Iowa landscape (Table 1) show that milkweeds declined in both agricultural fields and non-agricultural habitats from 1999 to 2010. There was a $31 \%$ decline for non-agricultural milkweeds and an $81 \%$ decline for agricultural milkweeds with a $58 \%$ overall decline for total milkweeds. In 1999, milkweeds in agricultural fields constituted $53 \%$ of total milkweeds, but by 2010 were only $24 \%$ of the total. The $58 \%$ loss of milkweeds on the landscape actually underestimates the loss of resource for monarchs, because most

Table 2. Maximum eggs per milkweed stem July through August for agricultural and non-agricultural sites in Iowa where ' $n$ ' is the number of fields examined. Egg densities on milkweeds in agricultural fields were significantly higher than on milkweeds in nonagricultural habitats in each year (2000: $t=3.97$, d.f. $=11 ; 2001: t=2.90$, d.f. $=4 ; 2002: t=3.35$, d.f. $=4: t=4.54$, d.f. $=5$; all $P$-values $<0.02)$.

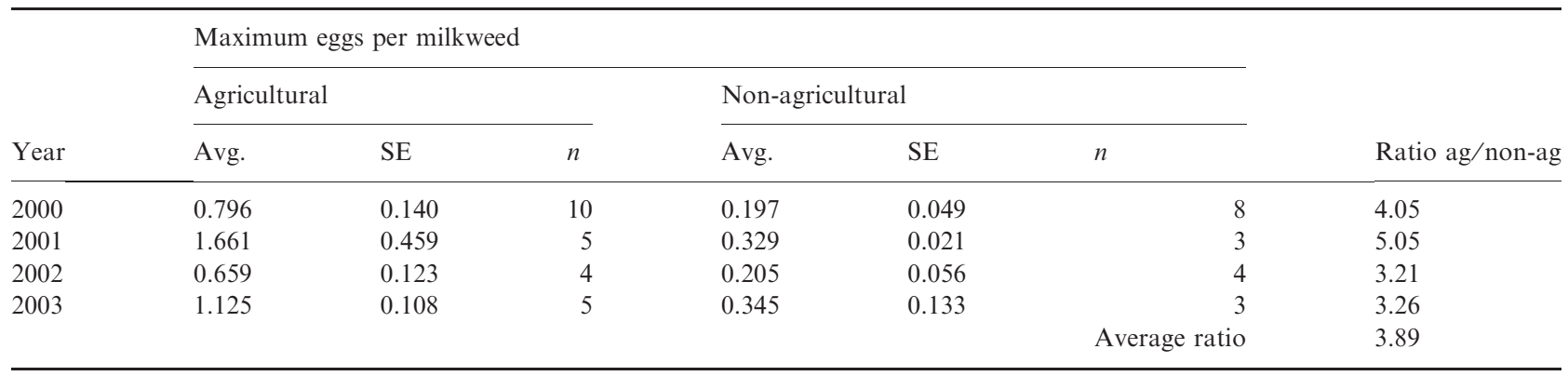


Table 3. Estimate of egg production in the Midwest from 1999 to 2010 . Note that values in the final three columns are relative; egg

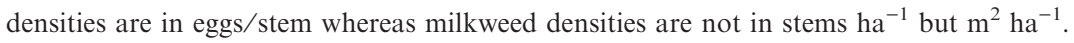

\begin{tabular}{|c|c|c|c|c|c|c|c|}
\hline Year & $\begin{array}{l}\text { Total non-ag } \\
\text { milkweeds* }\end{array}$ & $\begin{array}{l}\text { Total ag } \\
\text { milkweeds* }\end{array}$ & $\begin{array}{l}\text { Eggs/ } \\
\text { plant-non-ag } \dagger\end{array}$ & $\begin{array}{l}\text { Eggs/ } \\
\text { plant-ag† }\end{array}$ & $\begin{array}{l}\text { Production } \\
\text { non-ag§ }\end{array}$ & Production ag $\uparrow$ & Total production** \\
\hline 1999 & 185.4 & 213.2 & 0.243 & 0.945 & 45.0 & 201.4 & 246.5 \\
\hline 2000 & 187.1 & 183.8 & 0.144 & 0.796 & 26.9 & 146.3 & 173.2 \\
\hline 2001 & 195.0 & 155.4 & 0.299 & 1.661 & 58.3 & 258.2 & 316.5 \\
\hline 2002 & 191.5 & 133.4 & 0.197 & 0.659 & 37.6 & 87.9 & 125.5 \\
\hline 2003 & 184.7 & 115.8 & 0.173 & 1.125 & 31.9 & 130.2 & 162.1 \\
\hline 2004 & 177.9 & 99.4 & 0.102 & 0.395 & 18.1 & 39.3 & 57.4 \\
\hline 2005 & 172.0 & 85.2 & 0.205 & 0.796 & 35.2 & 67.8 & 103.0 \\
\hline 2006 & 167.5 & 72.8 & 0.277 & 1.077 & 46.4 & 78.5 & 124.9 \\
\hline 2007 & 161.4 & 62.8 & 0.274 & 1.066 & 44.2 & 66.9 & 111.1 \\
\hline 2008 & 146.6 & 54.4 & 0.154 & 0.599 & 22.6 & 32.6 & 55.2 \\
\hline 2009 & 135.7 & 46.9 & 0.120 & 0.465 & 16.2 & 21.8 & 38.0 \\
\hline 2010 & 127.4 & 40.3 & 0.311 & 1.210 & 39.6 & 48.7 & 88.4 \\
\hline
\end{tabular}

$* \mathrm{~m}^{2} \times 1000$; from Table 1 .

$\dagger$ from MLMP.

$\ddagger$ Non-ag eggs/plant $\times 3.89$ (ratio of ag to non-ag, see Table 2 ), except for 2000-2003 from Table 2.

$\S$ Total non-ag milkweeds $\times$ Eggs/plant non-ag.

$\uparrow$ Total ag milkweeds $\times$ Eggs/plant ag.

***oduction non-ag. + Production ag.

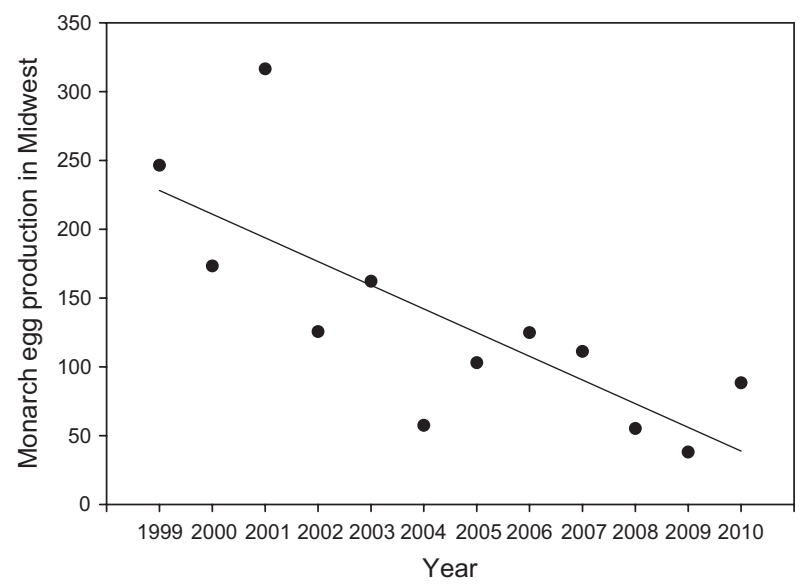

Fig. 2. Estimate of monarch production from the Midwest by year. Linear regression $F_{1,11}=13.7 ; P=0.004 ; r^{2}=0.58$.

of the loss was in agricultural fields and each agricultural milkweed represents 3.89 times more monarch eggs than a nonagricultural milkweed (Table 2). If the numbers of agricultural milkweeds in Table 1 are multiplied by 3.89 to convert them to their resource potential, the decline in the milkweed resource base is $72 \%$. Of this potential resource lost, $92 \%$ comes from agricultural fields and $8 \%$ from non-agricultural habitats. Table 3 shows the conversion of yearly milkweed numbers into monarch production. The relative contribution of agricultural milkweeds to total monarch production went from $82 \%$ in 1999 to $55 \%$ in 2010 .

There has been a significant decline in monarch egg production over the last decade (Fig. 2 - linear regression $F_{1,11}=13.7$, $\left.P=0.004, r^{2}=0.58\right)$. On the basis of regression equation for

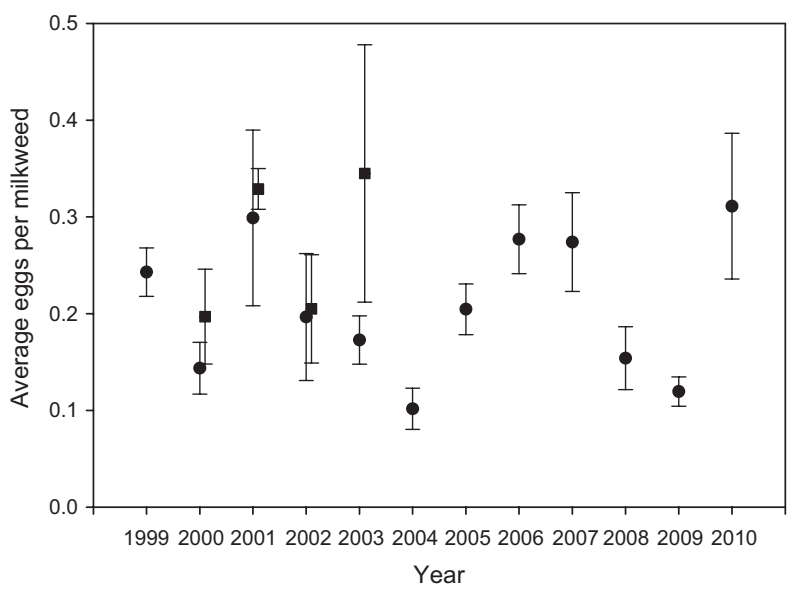

Fig. 3. Average maximum egg density (eggs per milkweed stem $\pm 1 \mathrm{SE}$ ) for July through August for non-agricultural milkweeds at sites throughout the Midwest (from MLMP). Number of sites: 1999, 16; 2000, 41; 2001, 13; 2002, 25; 2003, 41; 2004, 46; 2005, 49; 2006, 57; 2007, 29; 2008, 29; 2009, 30; 2010, 21. Square symbols indicate the average value $( \pm 1 \mathrm{SE})$ for non-agricultural sites in Iowa (from Table 2). The Iowa value for each year was not significantly different from the MLMP value.

this decline $(y=254.4-17.21 x$, where $x=1$ when the year is 1999), we estimate that between 1999 and 2010 monarch egg production in the Midwest was reduced $81 \%$. This decline in production would not have occurred if monarchs had increased their use of the remaining milkweeds as agricultural milkweeds declined. However, egg density on non-agricultural milkweeds from the MLMP data did not show a significant change over the years (Fig. 3) (because of non-normality, a Poisson regression was used; Wald $\chi^{2}=0.15$; d.f. $=1 ; n=398$, NS). We 
also compared our estimate of potential monarch production in each summer with the size of the population that subsequently overwintered in Mexico (Fig. 4). Yearly production values were positively correlated with the size of the overwintering population (linear regression $F_{1,11}=8.97, P=0.01, r^{2}=0.47$ ).

\section{Discussion}

Our estimate of monarch production decline in the Midwest was based in part on Iowa data. To what extent do Iowa data reflect the Midwest as a whole? We used Iowa data to estimate (i) the proportion of milkweed in various habitats, (ii) the density of milkweeds in each habitat, (iii) the decline in milkweeds in agricultural fields and (iv) the relatively higher egg density on agricultural milkweeds compared to non-agricultural milkweeds. We examine each of these aspects of the data. (i) Data on land use for the Midwestern states (Lubowski et al., 2006) show that of the potential milkweed habitat $73 \%$ was in crop production and $27 \%$ in non-agricultural habitats $6 \%$ in CRP land, $6 \%$ in cropland pastures, $11 \%$ in grassland and range pastures, and $4 \%$ in roadsides). This is similar to the $79 \%$ in crop production for the state of Iowa and $21 \%$ in non-agricultural habitats $(6 \%$ in CRP land, $5 \%$ in cropland pastures, $7 \%$ in grassland and range pastures and $3 \%$ in roadsides). Note that these values do not include forested land as this is not milkweed habitat. This comparison excluded the Northern Plains states (Kansas, Nebraska, N. and S. Dakota), which have extensive grasslands and rangeland in the western sections. If those states are included, the per cent of Midwest land in crops falls to $60 \%$ with $40 \%$ of land non-agricultural. (ii) Iowa data were used to estimate milkweed densities for agricultural and roadside habitats; the change in milkweed density in other non-agricultural habitats was based on Midwest MLMP data. There has not been a long-term study of milkweed density in agricultural habitats

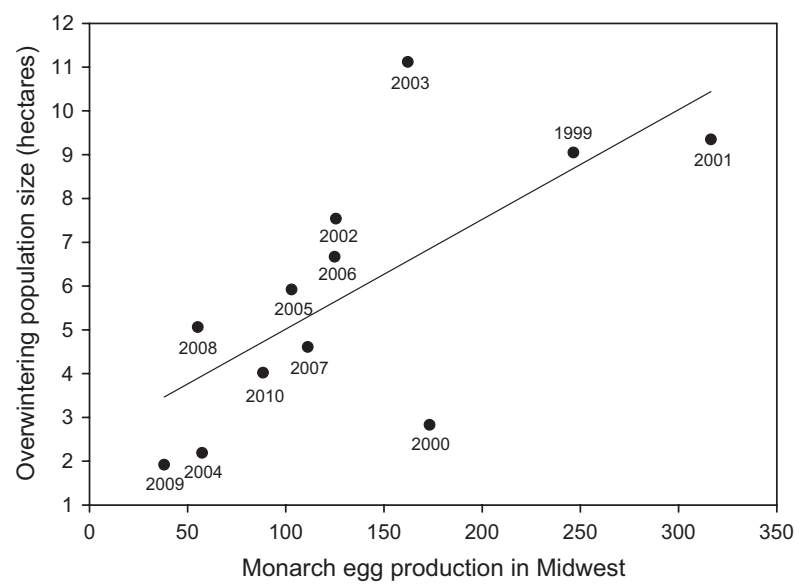

Fig. 4. Estimate of monarch production in the Midwest by year (from Table 3) compared with the size of the subsequent overwintering population in that year (from Rendón-Salinas et al., 2011). The size of the overwintering population is measured in hectares covered by butterflies. Linear regression $F_{1,11}=8.97 ; P=0.01$; $r^{2}=0.47$. outside of Iowa so the similarity between Iowa and the Midwest in this aspect can only be assumed. (iii) Other Midwest areas have seen a decline in milkweed density in agricultural fields over the past decade. Two of the Wisconsin fields originally surveyed by Oberhauser in 2000 (Oberhauser et al., 2001) were resurveyed in subsequent years. In 2000, these sites had an average of 0.28 milkweed stems $\mathrm{m}^{-2}$, and in 2002-2006, after the growers began to use glyphosate-tolerant soybeans in 2001, no milkweeds were found. (iv) Higher egg densities on agricultural milkweeds were also observed in other states in the Midwest in 2000 (Oberhauser et al., 2001).

Further evidence suggesting that our approach, which combines data from Iowa and Midwest sources, does reflect production for the Midwest as a whole comes from the significant positive correlation between the annual estimate of monarch production and the size of the subsequent overwintering population (Fig. 4). Because the Midwest contributes about half of the individuals to the overwintering population (Wassenaar \& Hobson, 1998), we would expect such a correlation if Midwest production were accurately estimated. We note, however, that the estimate of the Midwest contribution to the overwintering population was made before significant glyphosate use in row crops and only represents 1 year of data.

Although our estimates of annual Midwest monarch production were highly correlated with the size of the subsequent overwintering population, these estimates explained only $47 \%$ of the variation in the size of the overwintering population. In particular, our production value for 2003 underestimated the overwintering population size and our value for 2000 overestimated it. We suggest four possible reasons for such deviations. (i) Deviations may be due to the fact that we have used egg density as our measure of production, which is a measure of potential production, while actual production is adult butterflies. The relationship between potential and actual production will depend on survivorship from egg to adult, which may vary among years (J. M. Pleasants \& K. S. Oberhauser, unpubl. data). (ii) The relative contribution of the Midwest to the population as a whole is likely to vary from year to year (K. S. Oberhauser, unpubl. data). (iii) The amount of mortality during the fall migration is likely to vary among years depending on conditions along the migratory route including nectar availability, temperature, weather events, drought conditions and wind conditions. (iv) We used a factor of 3.89, the average of 4 years of Iowa data, to convert agricultural milkweeds into their monarch egg production. The factor varies among years, as seen in Table 2, and may be somewhat different in other areas of the Midwest.

The differences between years in egg density per stem seen in the MLMP data (Fig. 3) are likely to be caused by factors in addition to the effect of resource availability. The MLMP egg densities we used came from the second and third generation of monarchs. The size of each generation will depend on the size of the previous generation, each of which will be influenced by the prevailing weather conditions during egg laying and larval development (Zalucki \& Rochester, 2004). Although the overwintering population begins this sequence, we found no correlation between the size of the overwintering population and monarch production the following summer. This indicates that other factors, principally temperature and weather conditions, can erase 
the influence of the starting population. But environmental conditions alone do not govern population size. Even if favourable conditions exist, the potential production of the monarch population is dampened by the loss of milkweeds.

As previously mentioned, the loss of milkweeds in agricultural fields would not have affected total monarch production if monarch use of the remaining milkweeds, both agricultural and nonagricultural, had increased sufficiently. We do not have data on the use of agricultural milkweeds over the last decade but data from the MLMP indicate that there was no increase in use of non-agricultural milkweeds over this period (Fig. 3). In a modelling study, Zalucki and Lammers (2010) found that removing small patches of milkweed from the matrix (the area between larger patches of milkweed) made it harder for monarch females to achieve their egg production potential because of increased search time. In their model, a decrease in milkweed availability in the agricultural crop matrix, such as what would result from herbicide use, could significantly reduce the lifetime number of eggs laid by individual females.

Davis (2011) has suggested that there has been no downward trend in monarch production, based on monitoring data at two sites at which monarchs congregate during the fall migration. The monarchs that appear at these two sites, Peninsula Point in Upper Michigan and Cape May in New Jersey, are migrants from the Upper Peninsula of Michigan and south central Canada, and the Eastern United States, respectively. However, the isotope analysis of (Wassenaar and Hobson (1998) indicates that monarchs from these areas constitute a much smaller portion of the total monarch population than monarchs from the Midwest. Consequently, the lack of decline Davis observed will not reflect the population as a whole. Similar points have also been argued by Brower et al. (2011a).

The lack of decline in migrating Eastern monarchs, noted by Davis, further illustrates the connection between glyphosate use in corn and soybean fields and monarch decline. Monarchs from the Northeast and Canada may not be experiencing a decline because they come from areas with less corn and soybean agriculture and thus less milkweed loss because of herbicide use. In 2010, there were 25.1 million soybean hectares and 25.5 million corn hectares in the Midwest but only 0.4 million soybean hectares and 0.7 corn hectares in the Northeast (USDA, National Agricultural Statistics Service, 2011c).

We estimated that monarch production in the Midwest had declined 81\% from 1999 to 2010. For comparison, there was a $65 \%$ decline in the size of the overwintering population over this same period (Brower et al., 2011b). The similarity of these percentages, and the fact that our estimate of Midwest production is strongly correlated with the size of the overwintering population, clearly show the dominance of Midwest production for the population as a whole. However, the fact that the size of the overwintering population has declined less than the population contribution from the Midwest reflects the mitigating effect of portions of the range of the species that are not dominated by corn and soybean agriculture and have not been impacted by milkweed loss. As the monarch production contribution from the Midwest declines, the relative contribution from other parts of the range increases. A reassessment of the production contribution of the Midwest and other parts of the range, such as that performed earlier by Wassenaar and Hobson (1998), would be useful.

The loss of milkweeds in agricultural fields is particularly devastating for the monarch population because agricultural milkweeds are more heavily used than non-agricultural milkweeds (Table 2). This difference in egg density could result if females that find patches of milkweeds in agricultural fields lay more eggs per stem or if more females find patches of agricultural milkweeds. Patch size is typically smaller in agricultural fields than in non-agricultural habitats (J. M. Pleasants \& K. S. Oberhauser, pers. obs.), and higher egg densities per stem are observed in smaller milkweed patches (Zalucki \& Suzuki, 1987). Monarch females may seek out smaller patches and oviposit more heavily there, perhaps because small patches tend to support greater larval success (Zalucki, 1981; Zalucki \& Kitching, 1982). Greater oviposition by individual females may also be due to their perception of agricultural milkweeds as being of higher quality. Agricultural milkweed leaves have higher nitrogen content (J. M. Pleasants, unpubl. data) and tend to be in better condition. Finally, the milkweed chemical signal that attracts monarch females may be more apparent against the monoculture background of agricultural fields making it easier for females to find milkweeds in this habitat.

One unexpected finding in this study was the decline in milkweed density in non-agricultural habitats based on measurements by MLMP volunteers. These patches were not chosen at random, and it is possible that this decline is not representative of milkweeds in non-agricultural habitats across the landscape. Milkweed is a disturbance species and as such we would expect colonisation of disturbed areas followed by a population increase for a number of years and then a population decline as milkweed is outcompeted by later successional species. Monitored patches were chosen because they contained high milkweed densities. Thus, they may represent populations that had already experienced some growth and were now in the declining phase. A more thorough survey of milkweed densities in randomly chosen non-agricultural habitats over time is needed. If milkweed densities in non-agricultural habitats are not declining, then the loss of monarch production is not as large as we have estimated. We reran our calculations assuming no decline, and the estimated loss of monarch production from 1999 to 2010 was $76 \%$, somewhat lower than the $81 \%$ decline estimated using decreasing milkweed densities in non-agricultural habitats.

Given the disappearance of milkweeds in agricultural fields, milkweeds present in other habitats become more important for monarch populations. Table 1 indicates that the habitat of greatest importance is CRP land. However, the amount of CRP land is also declining; in 2010, the number of CRP hectares for the Midwestern states had declined by 0.5 million from its high in 2007 of 3.8 million hectares (USDA, Conservation Programs, 2010). Farmers have a number of options with regard to what types of vegetation to use as cover on CRP land, with grasses predominating. Adding forbs, including milkweeds, to planting mixes would provide nectar sources that could benefit many insect species and provide host plants for monarchs. While persuading farmers to include milkweed seed in the mix may be difficult, milkweed is capable of colonising such habitats on its own 
and education efforts about the value of milkweed and the many non-weedy milkweed species available are underway (Monarch Joint Venture, 2011). Further research needs to be undertaken on CRP land to see how different types of cover vegetation and land management practices affect milkweeds and monarchs.

Roadsides can provide important milkweed habitat; in 2010, $20 \%$ of the milkweeds were in roadsides (Table 1), and this value will increase as the remaining agricultural milkweeds disappear. The treatment of roadsides by departments of transportation could influence their value to monarchs. Roadsides are often mowed and sprayed with herbicides to eliminate forbs but roadside management plans compatible with monarch conservation could be developed. Many states are implementing programmes to plant native species along roadsides; such programmes could consider adding milkweeds.

We have not yet seen the full impact that the use of glyphosate herbicides and the consequent reduction in milkweed resources will have on the monarch population. At present, some milkweeds still remain in agricultural fields. Given the established dominance of glyphosate-tolerant crop plants and widespread use of glyphosate herbicide, the virtual disappearance of milkweeds from agricultural fields is inevitable. Thus, the resource base for monarchs in the Midwest will be permanently reduced. This will set a new, lower ceiling for monarch population size. A lower population size could lead to greater vulnerability of the population to deforestation on the overwintering sites and to extreme weather events or climate changes on the overwintering sites, in breeding areas and along migratory routes (Brower et al., 2011b).

\section{Acknowledgements}

We would like to thank the many citizen scientists who provided data for the Monarch Larva Monitoring Project. The National Center for Ecological Analysis and Synthesis, in a grant to S. Altizer, L. Ries, and Oberhauser, supported initial analysis of the MLMP data, and the National Science Foundation (ISE 0104600 and ISE 0917450 to KSO) supported development of the MLMP. We thank the Alliance WWF-Telcel for their support of Monarch Monitoring in the MBBR in Mexico, the farmers who allowed Pleasants access to their fields, and Lincoln Brower, Diane Debinski, Rick Hellmich, Steve Malcolm, Barbara Pleasants and O.R. Taylor for reviews of the manuscript and useful discussions about the results of this study.

\section{Author contributions}

J.P. performed field studies in Iowa, analysed the data and was primarily responsible for writing the article. K.O. supervised the collection and collation of the data from the MLMP and participated in the writing of the article.

\section{Competing financial interests}

The authors declare no competing financial interests.

\section{References}

Bhowmik, P.C. (1994) Biology and control of common milkweed (Asclepias syriaca). Reviews of Weed Science (ed. by S.A. Duke), Vol. 6, pp. 227-250. Weed Science Society of America, Champaign, Illinois.

Brower, L.P., Taylor, O.R. \& Williams, E.H. (2011a) Response to Davis: choosing relevant evidence to assess monarch population trends. Insect Conservation and Diversity. doi: 10.1111/ j.1752-4598.2011.00176.x

Brower, L.P., Taylor, O.R., Williams, E.H., Slayback, D.A., Zubieta, R.R. \& Ramirez, M.I. (2011b) Decline of monarch butterflies overwintering in Mexico: is the migratory phenomenon at risk? Insect Conservation and Diversity. doi: 10.1111/j.17524598.2011.00142.x.

Cockrell, B.J., Malcolm, S.B. \& Brower, L.P. (1993) Time, temperature, and latitudinal constraints on the annual recolonization of eastern North America by the monarch butterfly. Biology and Conservation of the Monarch Butterfly (ed. by S.B. Malcolm and M.P. Zalucki), pp. 234-251. Science Series No. 38. Natural History Museum of Los Angeles County, Los Angeles, California.

Davis, A.K. (2011) Are migratory monarchs really declining in eastern North America? Examining evidence from two fall census programs. Insect Conservation and Diversity. doi: 10.1111/ j.1752-4598.2011.00158.x.

Goehring, L. \& Oberhauser, K.S. (2002) Effects of photoperiod, temperature and host plant age on induction of reproductive diapause and development time in Danaus plexippus. Ecological Entomology, 27, 674-685.

Hartzler, R.G. (2010) Reduction in common milkweed (Asclepias syriaca) occurrence in Iowa cropland from 1999 to 2009. Crop Protection, 29, 1542-1544.

Hartzler, R.G. \& Buhler, D.D. (2000) Occurrence of common milkweed (Asclepias syriaca) in cropland and adjacent areas. Crop Protection, 19, 363-366.

Herman, W.S. (1985) Hormonally mediated events in adult monarch butterflies. Migration: Mechanisms and Adaptive Significance (ed. by M.A. Rankin), pp. 799-815. 27 (Suppl). University of Texas Marine Institute Contributions to Marine Science, Austin, Texas.

Iowa State Agricultural Statistics (2010) < http://www. extension.iastate.edu/Documents/soils/acretrends.PDF $>$ 13th January 2011.

Lubowski, R.N., Vesterby, M., Bucholtz, S., Baez, A. \& Roberts, M.J. (2006) Major uses of land in the United States 2002. $<$ http://purl.umn.edu/7203 > 15th February 2011.

Malcolm, S.B., Cockrell, B.J. \& Brower, L.P. (1993) Spring recolonization of the eastern North America by the monarch butterfly: successive brood or single sweep migration? Biology and Conservation of the Monarch Butterfly (ed. by S.B. Malcolm and M.P. Zalucki), pp. 253-267. Science Series No. 38, Natural History Museum of Los Angeles County, Los Angeles, California.

Martin, A.R. \& Burnside, O.C. (1980) Common milkweed-weed on the increase. Weeds Today, Early Spring, 19-20.

Monarch Joint Venture (2011) < http://www.monarchjointventure. org > 18th August 2011.

Monarch Larval Monitoring Project (2011) < http://www. mlmp.org > 15th August 2011.

Monarch Watch $(2011)<$ http://www.monarchwatch.org/ > 18th August 2011.

Oberhauser, K.S., Prysby, M.D., Mattila, H.R., Stanley-Horn, D.E., Sears, M.K., Dively, G., Olson, E., Pleasants, J.M., Lam, 
W.F. \& Hellmich, R. (2001) Temporal and spatial overlap between monarch larvae and corn pollen. Proceedings of the National Academy of Sciences USA, 98, 11913-11918.

Pline, W.A., Hatzios, K.K. \& Hagood, E.S. (2000) Weed and herbicide-resistant soybean (Glycine max) response to glufosinate and glyphosate plus ammonium sulfate and pelargonic acid. Weed Technology, 14, 667-674.

Prysby, M. \& Oberhauser, K.S. (2004) Temporal and geographical variation in monarch densities: citizen scientists document monarch population patterns. The Monarch Butterfly: Biology and Conservation (ed. by K.S. Oberhauser and M.J. Solensky), pp. 9-20. Cornell University Press, Ithaca, New York.

Rendón-Salinas, E., Valera-Bermejo, C.A., Cruz-Piña, M. \& Martinez-Meza, F. (2011) Monitoreo de las colonias de hibernación de mariposa monarca: superficie forestal de ocupación en Diciembre de 2010. World Wildlife Fund, Mexico, Mexico City. $<$ http://www.wwf.org.mx/wwfmex/descargas/rep-monitoreo-superficie-colonias-mariposa-monarca-alianza-wwf-telcel-DIC > 16th February 2011.

Solensky, M.J. (2004) Overview of monarch migration. The Monarch Butterfy: Biology and Conservation (ed. by K.S. Oberhauser and M.J. Solensky), pp. 79-83. Cornell University Press, Ithaca, New York.

United States Department of Agriculture. Economic Research Service (2011) Adoption of genetically engineered crops in the U.S. < http://www.ers.usda.gov/Data/BiotechCrops/> 1st July 2011.

United States Department of Agriculture. Conservation Programs (2010) < http://www.fsa.usda.gov/FSA/webapp?area = home\& subject $=$ copr\&topic $=$ crp-st $>11$ th January 2011 .

United States Department of Agriculture. National Agricultural Statistics Service (2011a) < http://www.nass.usda.gov/Surveys/ Guide_to_NASS_Surveys/Chemical_Use/ > 25th May 2011.

United States Department of Agriculture. National Agricultural Statistics Service (2011b) < http://usda.mannlib.cornell.edu/
MannUsda/viewDocumentInfo.do?documentID $=1560>25$ th May 2011.

United States Department of Agriculture. National Agricultural Statistics Service (2011c) < http://usda01.library.cornell.edu/ usda/current/Acre/Acre-06-30-2011.pdf > 30th June 2011.

Wassenaar, L.I. \& Hobson, K.A. (1998) Natal origins of migratory monarch butterflies at wintering colonies in Mexico: new isotopic evidence. Proceedings of the National Academy of Sciences of the United States of America, 95, 15436-15439.

Zalucki, M.P. (1981) Temporal and spatial variation of parasitism in Danaus plexippus (L.) (Lepidoptera: Nymphalidae, Danaidae). Australian Entomological Magazine, 8, 3-9.

Zalucki, M.P. \& Kitching, R.L. (1982) Temporal and spatial variation of mortality in field populations of Danaus plexippus L. and D. chrysippus L. larvae (Lepidoptea: Nymphalidae). Oecologia, 53, 201-207.

Zalucki, M.P. \& Lammers, J.H. (2010) Dispersal and egg shortfall in monarch butterflies: what happens when the matrix is cleaned up? Ecological Entomology, 35, 84-91.

Zalucki, M.P. \& Rochester, W.A. (2004) Spatial and temporal population dynamics of monarchs down-under: lessons for North America. The Monarch Butterfly: Biology and Conservation (ed. by K.S. Oberhauser and M.J. Solensky), pp. 78-83. Cornell University Press, Ithaca, New York.

Zalucki, M.P. \& Suzuki, Y. (1987) Milkweed patch quality, adult population structure and egg laying in Danaus plexippus (Lepidoptea: Nymphalidae). Journal of the Lepidopterists' Society, 41, 13-22.

Accepted 23 January 2012

Editor: Simon R. Leather

Associate editor: Thomas Schmitt 